\title{
Yutu rover reveals subsurface structure of the Moon
}

\author{
PING JinSong* \\ National Astronomical Observatories, Chinese Academy of Sciences, Beijing 100020, China
}

Received April 15, 2015; accepted April 16, 2015

Chinese lunar mission Chang'E-3 is the latest in-situ exploration to the Moon after the Apollo and Luna missions finished 40 years ago. It is composed of a lander and a rover (Yutu: named after the jade rabbit on the Moon in a Chinese fairy tale). Yutu rover is equipped with several scientific instruments including a lunar penetrating radar (LPR), whose measurement has never been carried out on a rover. After integrating the LPR data with other in-situ and geological informations, Xiao et al. [1] discovered several subsurface layers in northern Mare Imbrium, which reveals a much more complex geological history than previous thought.

The surface of the landing site is within the Eratosthenian materials [2], which is younger than those of the Apollo and Luna landing sites. In the landing area, impact craters with different sizes and degradations were observed. Among the fresh ejecta deposits, a $\sim 4 \mathrm{~m}$ long, $\sim 1.5 \mathrm{~m}$ high boulder (Loong Rock) is of particular interest. It looks homogeneous with the $\sim 1.5$ to $2 \mathrm{~cm}$ light color crystals in high resolution images taken by Panoramic Camera, and it is distinct in texture from the samples obtained by the Apollo missions.

The most significant advance is the subsurface structure revealed by LPR (Figure 1). LPR has two channels (Channel 1: $60 \mathrm{MHz}$ and Channel 2: $500 \mathrm{MHz}$ ), which were designed to detect subsurface layers with different depths and resolutions [3]: Channel 1 radar can disclose subsurface interface deep to $\sim 400 \mathrm{~m}$, while Channel 2 radar can "see" depth shallower than $12 \mathrm{~m}$ but with greater detail. LPR observed the interface of Eratosthenian and Imbrian, which is consistent with the thickness of Eratosthenian determined by impact crater [4]. In addition, several layers of paleoregolith were also detected, and they demonstrated the existence of intervals of different volcanic eruptions and subsequent space weathering processes. These thicknesses of the paleoregolith layers could help us understand the rate

*Corresponding author (email: jsping@bao.ac.cn) variations of space weathering through time. Besides the paleoregolith layers, LPR discovered several distinct layers that could be composed of pyroclastic materials. They revealed the changes of eruption style during emplacement of the Imbrian volcanic materials.

Several questions still need to be addressed in future study: 1) What were the conditions forming the coarsegrained Loong Rock? 2) What were the rates of space weathering in the Imbrian and what were the reasons for the rate variations? 3) What were the key elements controlling the changes of volcanic eruption and/or overflow style?

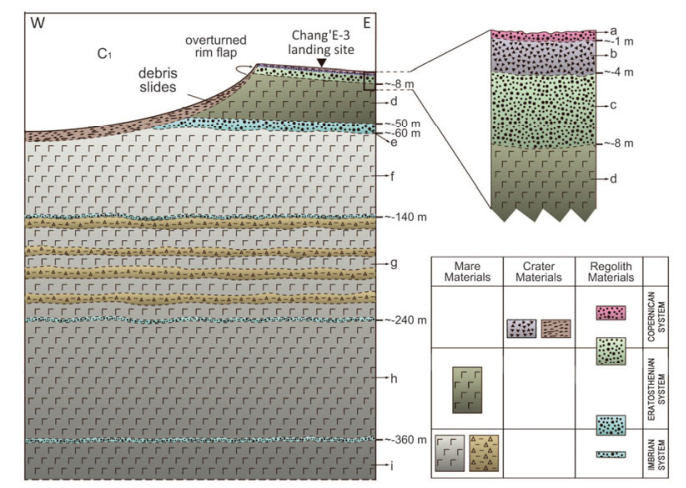

Figure 1 (Color online) Sketched geological cross section and an inferred profile of the CE-3 landing site. Yutu has detected seven subsurface interfaces, which formed from imbrian to Copernican. Letters from 'a' through 'i' indicate interpreted subsurface layers based on the LPR data (From Xiao et al. [1]).

1 Xiao L, Zhu P, Fang G, et al. A young multilayered terrane of the northern Mare Imbrium revealed by Chang'E-3 mission. Science, 2015, 347(6227): 1226-1229

2 Zhao J, Huang J, Qiao L, et al. Geologic characteristics of the Chang'E-3 exploration region. Sci China-Phys Mech Astron, 2014, 57(3): 569-576

3 Zhao N, Zhu P, Yang K, et al. The preliminary processing and analysis of LPR Channel-2B data from Chang'E-3. Sci China-Phys Mech Astron, 2014, 57(12): 2346-2353

4 Qiao L, Xiao L, Zhao J, et al. Geological features and evolution history of Sinus Iridum, the Moon, Planet Space Sci, 2014, 101(0): 37-52 